\title{
A Life Course Analysis on Mobile Use among Third Agers in China
}

\author{
Chen Guo \\ School of Media Communication, Creative Arts and Social Inquiry, \\ Curtin University, Australia \\ \{chen.guo1@postgrad.curtin.edu.au\}
}

\begin{abstract}
This study explores what influence mobile use among third agers in China from the perspective of individual experience in life course theory. Mobile phones are promising tools to improve life quality of elderly [1]. With the development of mobile internet and devices, mobile use ability begun to influence third agers' life quality. Life course theory on the other hand, refers an individual life transition as part of cluster of concurrent transitions and a sequence of transitions that affect each other [2] and argue that the essence of life course is the interaction of 'individual time', 'family time', and 'history time'. This study, focusing on individual time aspect, explores the relationship between mobile use ability and their distinct individual experience in life course. The study focuses on people aged between 50 and 70, who are referred to as being 'third age' [3]. Largely research on mobile phone use focuses on young generations. Relatively few studies have been conducted on people around retirement age, a group termed 'third age' [3,4]. Third age is now seen as an important stage of life, and is described by life course theory. Third agers were not born in digital time, but they have accumulated digital capacities and acquired familiarity with technology, which has been termed as 'digital literacy' by Paul Gilster [5], now they need to face mobile world when they are old. Based on 6 in-depth interviews of mobile phone use in second tier cities in China in 2018, this study found individual experiences contribute to levels of mobile use ability amongst Chinese third agers. Mobile use ability in turn influences retired life quality.
\end{abstract}

Keywords: Digital Literacy; Life Course; Individual Experience; Mobile Use; Third Age

\section{Introduction}

Since 1994, when the internet was first introduced in China, the nation has attracted more internet users than any other country; by the end of 2018, the number was 829 million [6]. In China, the mobile phone has become a pervasive tool in people's daily life; in 2018 mobile phone users constituted $97.5 \%$ of the total internet users in China [7]. 'Mobile use only', that is, people use the mobile phone only to go online, has become a phenomenon. This phenomenon is particularly relevant for people who no longer work full time. People around 
their retired age have reasons to only use mobile devices; after retirement most don't need to use computers anymore; almost everything done on computer can be replaced by mobile phone; the mobile phone can be accessed anywhere and anytime.

Research on mobile phone use mostly focuses on younger generations. Relatively few studies have been conducted on people around retirement age, a group described by Laslett as being in their 'third age' $[3,4]$. Third age represents the transition group with increased longevity, better health [8] and the stage of 'personal achievement and fulfilment' [4]. Nowadays, Chinese 60 plus population, who number approximately 249 million, reached to $17.9 \%$ of total population [9] increasingly engage in the digitalized world and their ability to adapt to a mobile environment had become critical to their life quality.

In this paper I will examine mobile use in China among third agers from the perspective of individual experience,although life course framework contains three aspects, including individual experience, linked lives and historical social events. This study only focuses on the influence of individual experience to mobile use. From the perspective of life course, Chinese third agers' use of mobile media is not merely influenced by current situations, but is also influenced by their distinct life course, including early life experience, linked lives and historical social events. Here, individual experience will be discussed only.

This article begins by introducing the concept of life course. Then the study provides some previous research relating to technology use among the aging population, and discusses the concept of digital literacy briefly. In the next sections the article briefly discusses the methods used in the research before applying the discussion of findings to individual experience of life course framework. Finally, I offer some conclusions about the usefulness of life course theory with respect to mobile use ability among third agers in China's second tier cities.

The most cited definition of life course comes from Elder [10]: "a sequence of age-linked transitions that are embedded in social institutions and history". Mortimer and Shanahan have defined life course as 'age-graded, socially-embedded sequence of roles that connect the phases of life' [11]. Hareven and Adams [12] claimed as "an individual life transition". They further argued that a cohort belongs to its specific time as well as historical time. Hareven and Adams examined the life course framework from individual time, family time and historical time (i.e. the life course and aging in historical perspective). Hence, three main themes are foregrounded - individual experience, linked lives and historical times.

This study only focuses on the individual experience of life course theory. But this is not to deny that the three themes influence each other. From this perspective, older people are not viewed simply as a "homogeneous group, but rather as age-cohort moving through history" [2], with individual distinct life experiences, influenced by the historical circumstances.

Digital literacy is one of the topics relating digital inequalities among aging population in the cross-discipline of media and gerontology. From the perspective of life course, digital literacy was accumulated by individual life course. Digital literacy was defined by Paul Gilster in 1997 as the 'the ability to understand and use information in multiple from a wide range of sources when it is presented via computer' [5]. Jo defines it as 'the ability to use technology confidently, creatively and critically to satisfy the needs in a digital society' [13]. As we entered the mobile society, concept of mobile literacy emerges. Mobile literacy means 'the ability to navigate, interpret information from, contribute information to, and communication through the mobile internet, including an ability to orient oneself in the space of the internet of things and augmented reality [14].

Looking through the evolution of concepts, we can see how it moves from computer to mobile internet. Although there exists some differences, all of them point out that adopting new digital world is important. The ability to adapt to using digital technologies can affect an 
individual's life quality [15]. In the digitalized world, people "cannot avoid accepting new technologies as the new technologies are pervasive and heavily marketed", otherwise "nonadoption comes with cost" [15]. Specific to the transitional group - third agers, their distinct individual experience, family relationship, and historical events, leads to diverse mobile use ability among them.

Looking through the previous studies relating to aging population and technology, most have focused on one specific factor or single aspect, for instance, some studies are mainly about how to use digital technology to solve the age related problems, such as physical declining including age related disability and diseases [16], mental declining including memory and cognition declining [17-19] and so on. Meanwhile other studies in this field are mainly about social and cultural participation based on social media use [20], and the cultural representation [21], new identity [22], and social reconstruction of aging population through using social media $[23,24]$. But most of them did not explore from a dynamic process to study aging population and their mobile use. Especially for the quantitative study, largely studies did not connect the current situation that the aging population face now with their historically cumulative experiences. Moreover, most of the studies regard the aging population as a homogeneous group, but in fact, because of the distinct individual experience, the aging population has huge difference. These difference also is reflected to their technology use and digital capital.

However, few study to date has examined mobile use amongst the aging population from the dynamic life course aspect, especially the individual experience aspect. Life course has been applied in various fields. Largely studies of life course focused on the inequality on aging population. The different mobile use abilities of the aging population represents a kind of inequality. As the society is digitalized and mobilized amongst every field of the society, the ability of mobile use begun to influence individual life quality [15]. Without mobile use ability or with low mobile use ability, the life quality and living cost will increase in the digital and mobile society.

In light of the life course theory, this study explores the various mobile use ability among third agers in China from the perspective individual experience. Other two themes, including linked lives and historical events, interact with the individual experience definitely. However, individual experience is the major reason that lead to individual differences. This study will show a dynamic and longitudinal individual experience trajectory of my participants.

\section{Method}

According to The Report of Aging mobile Internet Users[25], 38\% of the entire population of "aging" internet users in China are located in second tier cities. Yet research about digital technologies among the aging population tends to focus on developed areas such as Shanghai $[26,27]$ and Hong Kong [28, 29]. By comparison, few studies focus on the second-tier cities. In an attempt to address this research gap, this research conducted semi-structured interviews in the second-tier cities. Between January and February 2018, six third age participants attended the first-round interview in China. Follow-up interviews were conducted during July to September in 2018. Participants were both male and female and aged between 50 and 70.

Semi-structured interview is a verbal interchange by asking questions and based on a list of predetermined questions [30]. Although semi-structured interview has some prepared and structured questions, it can also ensure flexibility in the process of collecting information, which give my participants enough freedom to explain their life course experience. This study 
uses semi-structured interviews focused on the meanings and interpretation of individual experience, linked relationship with others and historical events.

In this study, the individual's mobile use ability is influenced by three main aspects, including individual experience, linked lives and historical events. Although some scholars explored other aspects, such as marriage or leaving house, parenthood or criminal behaviour [31], or even family background under the context of Great Culture Revolution by Chinese scholar [32], they selected different aspects for different research purpose. This study is focusing on Chinese third agers' mobile use ability, so the individual experience will be selected.

Moreover, based on previous study, the three main aspects were justified by pervious scholars in life course study. Hareven and Adams [12] argue that the essence of life course is the interaction of 'individual time', 'family time', and 'history time'. Similar Thorsen [33] expressed that the life course approach focuses on the 'multidimensional meaning of time; individual time (aging), cohort and historical time. It can be concluded that individual experience, linked lives and historical experience are the key three aspects of life course. The three topics almost cover all the life transitions and trajectories in the whole life course and they influence each other. All the three topics relate to each other. As the purpose of this study is to examine the mobile use ability among aging population, the individual experience was selected in this study.

\section{Results and Discussion}

\section{Individual Experience}

As mentioned earlier in the paper, every individual is unique of their distinct life experiences. According to Hareven and Adams [2], the life course experience, recognises that as people become older, they become even less like their peers than younger people. Similar argument can be found in the work relating to digital games [34].

Firstly, health is the most important factor that can influence participants' engagement in mobile use and their mobile use directly. Participant WSB, with Bachelor degree, worked in the publicity department of a stated-owned enterprise for decades before retired in 2014 . He acquired some technology skill from his work experience. He liked taking photos and videos, he even worked part time as professional photographer in China and Australia after he retired.

During the interview, he said he joined several WeChat groups of aerial photography, learnt how to play violin from mobile apps, and how to adjust tone using mobile tune adjust app. Participant WSB, using his photo and video editing skills, recorded happy family time regularly and mixed edited his own violin playing with roller skating and some aerial photography video. His life course of education background, work experience in publicity department, positive attitude of technology, and his life attitude, all cumulated to advantages for his mobile use ability.

Compared with Participant WSB, participant LHXB is male, with a bachelor degree. He worked in the army for more than 10 years and then worked for government until he retired in 2013. He took a positive attitude towards technology and mobile use, but he did not use a smart phone regularly. Because he suffered high blood pressure for several years and could not control his trembling hands so he always click wrongly. He preferred to ask her daughter to help him to buy something online, click something, and even transfer the money by APP 
bank. He would tell his password to his daughters. The mobile use ability of participant LHXB is influenced by health.

Different from previous study, the research found that education background in one's life course has limited influence on my participants' mobile use ability. The reasons may be, firstly, , mobile apps and devices, especially the apps my participants used are quite userfriendly, such as Wechat, Wesing, Alipay; secondly, my participants expressed that once they found something difficult they would skip it and seek alternatives.

It seems education background does not play an important role to their mobile use ability. Among my participants, participant CXM is female and participant WLLS is male, who only got middle high school degree and high school degree during their youth. However, they can use technologies, such as computer, mobile phone and apps, better than participant FFB who got Bachelor degree. They are all healthy enough to use mobile apps. This finding is different from previous research that it seems mobile use ability does not relate to education so closely. The reason why they acquired relatively different mobile use ability perhaps largely comes from individual health condition.

Except individual health and education background, individual working experience has obvious influence on my participants' mobile use ability. Participant CXM was a blue-collar worker before the laid off wave (compulsory retirement earlier than retirement age) in China in 1990s. According to her saying, the feeling of laid off is like "be abandoned by society". Then she started her family business. As the owner of family run business, she is afraid of being abandoned again by the society. So she begun to learn how to use Photo Shop software, how to install camera in the shop and connect with customer and family computer; how to use QR code to receive money; how to transfer money to other person through different apps. Overall, because of her working experience in her life course, she cumulated relatively high ability of mobile use than others.

The work experience played an important role in participant WLLS'S mobile use ability. The individual experience of participant WLLS's life course showed similar trajectories. He experienced laid off wave in his life course in 1990s too. Then he sought for some work opportunities in the medial facilities as a salesman. He is proud of his achievement and earns more money than before. His family life quality has become better than before. As he needs to travel a lot to do business, so he regard smart phone as a "companion". No matter on the train or long-distance bus, or stay in hotel by himself, he can use phone to kill some boring time. He has mastered a lot of practical skills of smart phone, such as group purchase app, delivery app, and booking tickets apps. Most the apps he is using is based on his work and need, still some relates with emotional attachment. The working experience in his life course accumulated advantages for his digital capital.

Participant ZTM worked as senior manager for a private company, and felt she must keep pace with social development, even after her retirement in order to catch up with the development of digital technology. According to her interview, she though the working experience in a private company cultivated her desire to catch up with the social development, otherwise her work can be replaced by others easily. So she is open to new technologies, including using the newest mobile IPhone $\mathrm{X}$ and eager to try Huawei mate 30 pro.

Compared with participant CXM and WLLS, participant FFB (a male) worked for the government. According to participant FFB, he could not upload contents or pictures on social media as he worried others who would regard this as showing off of his life, or bad persons will report his behaviour to discipline of inspection and supervision. Moreover, as a government officer, he thought if he updates regularly, the image and social identity of him is not consistent with the request of government and the Communist Party. 
Meanwhile, as he is one of the important officers in the government department, his secretary can help him to deal with most online tasks, which seems convenient for him now, but will hinder his mobile use in the long run. He expressed "relying on my secretary in the office, and relying on my daughter at home, I don't need to learn how to use mobile devices". As he got used to this "passive help", not "learn actively" how to operate practically, his mobile use ability is not so high. The reason for this is mainly because of his working experience in his life course.

During my interviews, I found that participant who have a positive and active personality, and who have a positive attitude toward using technology, can use mobile apps better than others. Gee and Elder [35] have mentioned the lack of research on personality and psychological aspects in life course field. The findings of my study implied that personality or psychological condition should be considered into life course concept.

Overall, personal health of individual life course is the most influential factor that can affect individual's digital use ability. Moreover, individual education background does not have much influence to mobile use among third agers in China, which is different from previous. Another finding is that individual work experience in one's life course has important influence to digital mobile use ability. The last is about individual attitude towards technology. My participants who think that the mobile use is useful and helpful for their lives, they can use their technology and mobile apps better in their daily lives.

Moreover, another finding is that chronological age does not affect much to my participants' digital use ability. This result is associated with previous scholars' argument [3638], they also argue that age is not the decisive factor to influence their technology use.

\section{Conclusion}

This study explored the relationship between digital inequalities - mobile use ability and individual experience in life course approach, and came to the conclusion that the influence of distinct life course lead to different degrees of mobile use ability among Chinese third agers. This paper not only considers specific factor or stage in the individual trajectory of life course, such as education trajectory or working trajectory, but applied life course theory to explore third agers' mobile use from longitudinal individual experience. Individual experience accumulated (dis)advantages of different mobile use ability among third agers in China. China is becoming into a digital China. The third agers in China cannot avoid to increasingly engage into digital world. The different mobile use ability among third agers influence their daily life quality. Just like Park argues that in the digitalized world, people without or with low mobile use ability comes with increasing living cost [15]. One of the limitation in this study is that this study only explore one aspect - individual experience, in life course theory. However, life course theory contains three aspects, including individual experience, linked lives and historical events; all the three aspects influence each other and lead to distinct life course. The individual experience lead to difference to third agers, meanwhile the individual experience intertwined with linked lives and historical events. Another limitation is that participants sample is not big enough. Longitudinal and broader research should be conducted in future. It will be quite meaningful if the study can compare how the third agers in different decades use technology in different ways, to illustrate the influence of different life course. Further study should explore the mobile use ability from the whole three aspects of life course theory. This is because the three aspects interact with each other, and influence the mobile use ability dynamically. Vice versa, the mobile use ability is influencing third agers' daily life. 


\section{References}

[1] I. Plaza, L. MartíN, S. Martin, and C. Medrano, "Mobile applications in an aging society: Status and trends," Journal of Systems and Software, vol. 84, no. 11, pp. 19771988, 2011.

[2] T. K. Hareven, "The life course and aging in historical perspective," in Ageing and Life Course Transitions: An Interdisciplinary Perspective, T. K. Hareven and K. J. Adams Eds. London and New York: Tavistock Publications, 1982.

[3] P. Laslett, "The emergence of the third age," Ageing and Society, vol. 7, no. 2, pp. 133 160, 1987.

[4] P. Laslett, A fresh map of life: The emergence of the third age. Massachusetts: Harvard University Press, 1991.

[5] P. Gilster and P. Glister, Digital literacy. New York: Wiley Computer Pub, 1997.

[6] CNNIC, "The 43rd Statistical Report on Internet Development in China ", 2019. [Online]. Available: http://www.cnnic.cn/hlwfzyj/hlwxzbg/hlwtjbg/201902/t20190228_70645.htm

[7] CNNIC, "The 41st Statistical Report on Internet Development in China," 2018. [Online]. Available: https://cnnic.com.cn/IDR/ReportDownloads/201807/P020180711391069195909.pdf

[8] R. S. Weiss and S. A. Bass, Challenges of the third age: Meaning and purpose in later life. Oxford University Press on Demand, 2002.

[9] (2019). The opinion of initiating healthy China from the state council. Original title: 国 务院关于实施健康中国行动的意见 [Online] Available: http://www.gov.cn/zhengce/content/2019-07/15/content 5409492.htm

[10] G. H. Elder Jr, Life course dynamics: trajectories and transitions 1968-1980. Ithaca: Cornell University Press, 1985.

[11] J. T. Mortimer and M. J. Shanahan, Handbook of the life course. Springer Science \& Business Media, 2007.

[12] T. K. Hareven and K. J. Adams, Ageing and life course transitions: An interdisciplinary perspective. Routledge, 1982.

[13] C.-N. Jo. "What is digital literacy?" https://developingemployability.edu.au/what-isdigital-literacy/ (accessed.

[14] N. Hockly, G. Dudeney, and M. Pegrum, Digital literacies. Routledge, 2014.

[15] S. Park, Digital capital London: Palgrave Macmillan UK, 2017.

[16] J. L. Helbostad and B. Vereijken. "Activity app for an aging population." Peter Vermeiren. http://www.preventit.eu/index.php/news_events/activity-app-for-an-ageingpopulation/ (accessed.

[17] S. J. Czaja and C. C. Lee, "The impact of aging on access to technology," Universal Access in the Information Society, vol. 5, no. 4, pp. 341-349, 2006, doi: 10.1007/s10209-006-0060-x.

[18] B. Drew and J. Waters, "Video games: Utilization of a novel strategy to improve perceptual motor skills and cognitive functioning in the non-institutionalized elderly," Cognitive Rehabilitation, 1986.

[19] M. E. Pollack, "Intelligent technology for an aging population: The use of AI to assist elders with cognitive impairment," AI magazine, vol. 26, no. 2, p. 9, 2005.

[20] E. Hargittai and G. Walejko, "The participation divide: Content creation and sharing in the digital age," Information, Communication \& Society, vol. 11, no. 2, pp. 239-256, 2008, doi: 10.1080/13691180801946150. 
[21] C. Craciun and U. Flick, "I wonder if robots will take care of me when I am old: Positive aging representations of professionals working in health promotion services," Journal of Health Psychology, vol. 21, no. 12, pp. 2872-2881, 2016, doi: $10.1177 / 1359105315587141$.

[22] D. Rodan, K. Ellis, and P. Lebeck, Disability, obesity and ageing: popular media identifications. Farnham: Farnham : Ashgate Publishing Ltd, 2014.

[23] C. E. Buse, "E-scaping the ageing body? Computer technologies and embodiment in later life," Ageing and Society, vol. 30, no. 6, pp. 987-1009, 2010, doi: 10.1017/S0144686X10000164.

[24] J. Baars, "The challenge of critical gerontology: the problem of social constitution," Journal of Aging Studies, vol. 5, no. 3, pp. 219-243, 1991.

[25] Tencent, "The report of the aging mobile internet users. Original title: 老年用户移动 互 联网报告 ", 2018. [Online]. Available: https://www.cnbeta.com/articles/tech/724817.htm

[26] $\mathrm{H}$. Wu, "Elderly people and the Internet: a demographic reconsideration," in Handbook of cultural and creative industries in China, M. Keane Ed.: Edward Elgar Publishing, 2016.

[27] B. Xie, "Information technology education for older adults as a continuing peerlearning process: A Chinese case study," Educational Gerontology, vol. 33, no. 5, pp. 429-450. [Online]. Available: https://www-tandfonlinecom.dbgw.lis.curtin.edu.au/doi/full/10.1080/03601270701252872

[28] K. Chan, A. Wong, and E. Tam, "The use of smart phones and their mobile applications among older adults in Hong Kong : an exploratory study," GSTF journal of nursing and health care 2014, doi: 10.5176/2345-718X_1.2.45.

[29] K. Chen and A. H. S. Chan, "Predictors of gerontechnology acceptance by older Hong Kong Chinese," Technovation, vol. 34, no. 2, pp. 126-135, 2014/02/01/ 2014, doi: https://doi.org/10.1016/j.technovation.2013.09.010.

[30] G. Valentine and N. J. Clifford, Eds. Key methods in geography. London: London : SAGE Publications, 2003.

[31] R. J. Sampson and J. H. Laub, "A life-course theory of cumulative disadvantage and the stability of delinquency," Developmental theories of crime and delinquency, vol. 7, pp. 133-161, 1997.

[32] W. Hu, "Heterogeneity of cumulation: The elderly differention under the life course approach, Chinese title 积累的异质性:生命历程视角下的老年人分化," Society vol. 29, pp. 112-130, 2009, doi: 10.15992/j.cnki.31-1123/c.2009.02.006.

[33] K. Thorsen, "Et livsløpsperspektiv på aldring," Nordisk Psykologi, vol. 57, no. 1, pp. 64-85, 2005/01/01 2005, doi: 10.1080/00291463.2005.10637361.

[34] C. Guo, K. Ellis, and M. Kent, "Stigma verses Socio-cultural accessibility:-from the perspective of third age digital game players in China," in Gaming Disabilities, K. Ellis, M. Kent, and T. Leaver Eds.: Routlege, in-press.

[35] E. M. Gee, "review works: life course dynamics: trajectories and transitions, 19681980 " Social Indicators Research, vol. 18, no. 4, pp. 425-428, 1986. [Online]. Available: http://www.jstor.org/stable/27520686.

[36] M. M. Baltes and L. L. Carstensen, "The process of successful ageing," Ageing and Society, vol. 16, no. 4, pp. 397-422, 1996, doi: 10.1017/S0144686X00003603.

[37] A. Bowling, "The concepts of successful and positive ageing," Family Practice, vol. 10, no. 4 , pp. 449-453, 1993. 
[38] M. Goldstein, "Aging and Life Course Transitions: An Interdisciplinary Perspective," vol. 86, M. Goldstein and T. Hareven, Eds., ed, 1984, pp. 1037-1037. 